\title{
Response of Taiga Ecosystems to Extreme Weather Conditions and Climate Anomalies
}

\author{
N. N. Vygodskaya ${ }^{a, b}$, A. V. Varlagin ${ }^{a}$, Yu. A. Kurbatova ${ }^{a}$, A. V. Ol'chev ${ }^{a}$, O. I. Panferov ${ }^{c}$, \\ F. A. Tatarinov ${ }^{a}$, and N. V. Shalukhina ${ }^{a}$ \\ Presented by Academician Yu.I. Chernov June 22, 2009
}

Received June 22, 2009

DOI: $10.1134 / \mathrm{S} 0012496609060258$

The resistance of the biosphere to external impacts is the key problem of modern ecology and geography in view of a vague response of modern ecosystems to current and future climate changes and increasing anthropogenic load $[5,10]$. Studies of climate changes clarify only possible delayed structural rearrangement of the modern vegetation cover, shift of vegetation zones, and changes in the productivity and reserves of the carbon pool for large regions. Various climate scenarios are considered, which assume different rates of economic development and changes in the discharge of greenhouse gases to the atmosphere, as well as historical analogues of the current and future climate [5].

On the other hand, describing extreme weather phenomena (EWP) and climate anomalies (CAs) in different regions is becoming a topical issue of modern climate studies [4]. The attention of researchers is focused on studying floods, droughts, tornados, and periods of abnormally high summer temperaturesi.e., the phenomena having dramatic adverse consequences for the social and economic sphere. Unfortunately, the effect of EWP and CA on ecosystems in general is studied very poorly [4]. It should be taken into account that EWP usually are not considered in common climate scenarios and can be hardly predicted by modern climate models. A priori, this means that

(1) the predictions of the rate and scope of responses of ecosystems to some average conditions of future climate will have errors owing to increasing climate instability; and

\footnotetext{
a Severtsov Institute of Ecology and Evolution, Russian Academy of Sciences, Leninskii pr. 33, Moscow, 119071 Russia

${ }^{b}$ Institute of Geography, Jan Kochanowski University, Kielce, 25406 Poland

${ }^{c}$ Department of Bioclimatology, Büsgen Institute, Göettingen University, Büsgenweg 2, Göettingen, 37077 Germany
}

(2) with allowance for different lags in natural processes occurring in different environments, direct and inverse relations, different degree of resistance of ecosystem components, etc., it is difficult to simulate in dynamics a delayed response of terrestrial ecosystems to climate extrema.

Apparently, a rapid response of natural ecosystems to EWP and CA in general usually does not have obvious social and economic consequences (except for harvest loss and forest fires). However, this does not diminish the necessity of studying delayed EWP and CA consequences, because it is they that, at the level of ecosystem processes, will determine the structural rearrangement of modern vegetation cover at the level of landscapes and biomes during climate changes [1].

However, at shorter time intervals, we already encounter the situations when EWP cause rearrangements of local and regional processes of energy and mass exchange (EME), including $\mathrm{CO}_{2}$ gas exchange. An example of a rapid response of the $\mathrm{CO}_{2}$ gas exchange in terrestrial ecosystems to EWP is the decrease in the primary forest productivity in Europe under abnormal weather conditions in August 2003 $[3,7]$.

The influence of changes in environmental conditions on an ecosystem is expressed primarily at the level of processes and only then at the level of spatial and species structure of the vegetation cover. For this reason, in studies of ecosystem response to EWP and $\mathrm{CA}$, the analysis of certain integrated parameters of ecosystem function, such as albedo and net $\mathrm{CO}_{2} / \mathrm{H}_{2} \mathrm{O}$ exchange is of primary interest. The net ecosystem $\mathrm{CO}_{2}$ exchange (NEE) an water evaporation are the fundamental ecophysiological processes and basic elements of biogeochemical and hydrological cycles. They characterize the state of ecosystems and their adaptation for environmental conditions. $\mathrm{CO}_{2} / \mathrm{H}_{2} \mathrm{O}$ exchange also affects climate via a complex of direct and inverse relations [10]. Therefore, within the framework of the classic problem of interaction between climate and vegetation, it is important to 


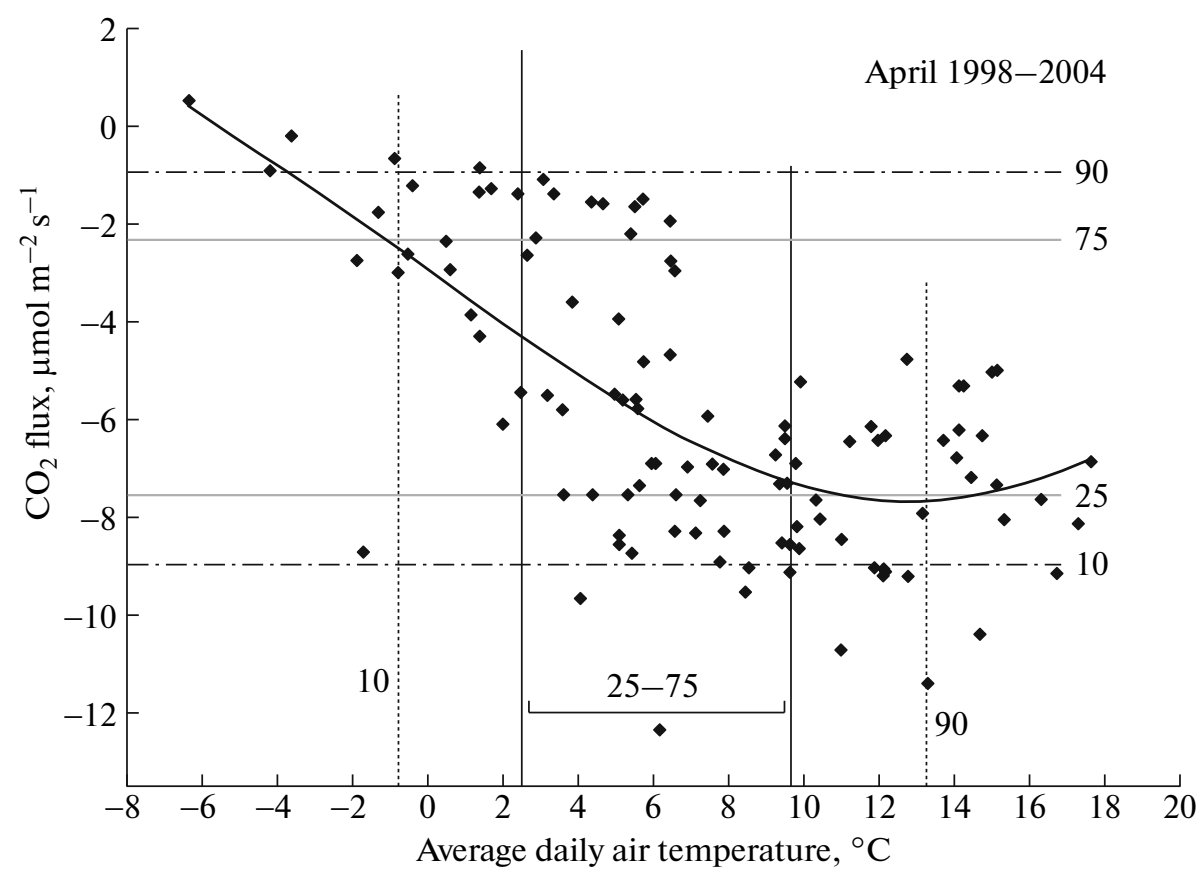

Fig. 1. $\mathrm{NEE}_{\max }$ response to the daily average temperature in April 1998-2004. Horizontal lines mark the threshold boundaries of $\mathrm{NEE}_{\text {max }}$ corresponding to the 10th, 90th and 25th-75th percentiles.

assess the resistance of the basic processes (first of all, photosynthesis, respiration, and evaporation) at the ecosystem level to environmental changes. This problem is especially relevant for boreal ecosystems under conditions of modern global warming.

Apparently, multiyear biophysical and biochemical studies of the same objects are required to assess the actual response of natural ecosystems to external effects. Such studies at the ecosystem level can be performed by the eddy-covariance technique [2]. This method for direct flux measurements makes it possible to study the dependences of integrated parameters of ecosystem function on climate parameters and to obtain data for parameterizing EME processes in numerical models.

To analyze the effects of EWP and CA on the NNE in spruce forests of different age, typical for southern European taiga, we used the results of continuous eddy-covariance measurements in two types of spruce forests in the Central Forest State Nature Biosphere Reserve (Tver oblast) [6]. To estimate the probability of extreme conditions for the flux measurement period since 1998, we analyzed a series of daily average and monthly average air temperatures $(T)$ and the cumulative precipitation $(P)$ measured at weather observation stations at Vyshnii Volochok and Fedorovskoe. The vegetation beginning dates were determined as described in [8].

It was established that, in the observation period since 1998, the climate in the study region was characterized by a high instability. In addition to EWP at the level of daily average data, CAs were recorded at the level of monthly, seasonal, and yearly values. In June 1999 , for the first time for the 114-year series of meteorological observation, simultaneous anomalies in $T$ and $P$ were recorded. On the basis of the dynamics of physiological processes and the significance of different factors for different processes, it is obvious that the effect of temperature, precipitation, and radiation anomalies is differentially manifested at different stages of vegetation development. The beginning of vegetation is the most meteorologically sensitive critical phenological phase.

Data presented in Figs. 1 and 2 show the NEE response to $T$ and $P$ for different averaging scales. The threshold $T$ and $P$ values were determined as multiannual 95 th and 5 th percentiles. $P$ percentiles vary in the range from $<5$ (very dry) to $>95$ (very moist); $T$ percentiles, from $<5$ (very cold) to $>95$ (very warm). The climatic norm corresponds to the 25 th and 75 th $P$ and $T$ percentiles, respectively.

The NEE response to an extreme decrease in the daily average $T$ (below the 10th percentile) is expressed in a drastic decrease in $\mathrm{CO}_{2}$ assimilation and in the change in the NEE sign (the $\mathrm{CO}_{2}$ flux is directed to the atmosphere). A very high $T$ (above the 90 th percentile) suppressed the NEE less significantly (the ecosystem absorbs $\mathrm{CO}_{2}$ from the atmosphere) (Fig. 1). The effect of high daily average temperature (in the 10 th to 25 th percentile range) is expressed within 45 days after subsequent decrease in $T$. In spring, the effect of precipitates is expressed only in the April temperature range of $7-10^{\circ} \mathrm{C}$. 
(a)
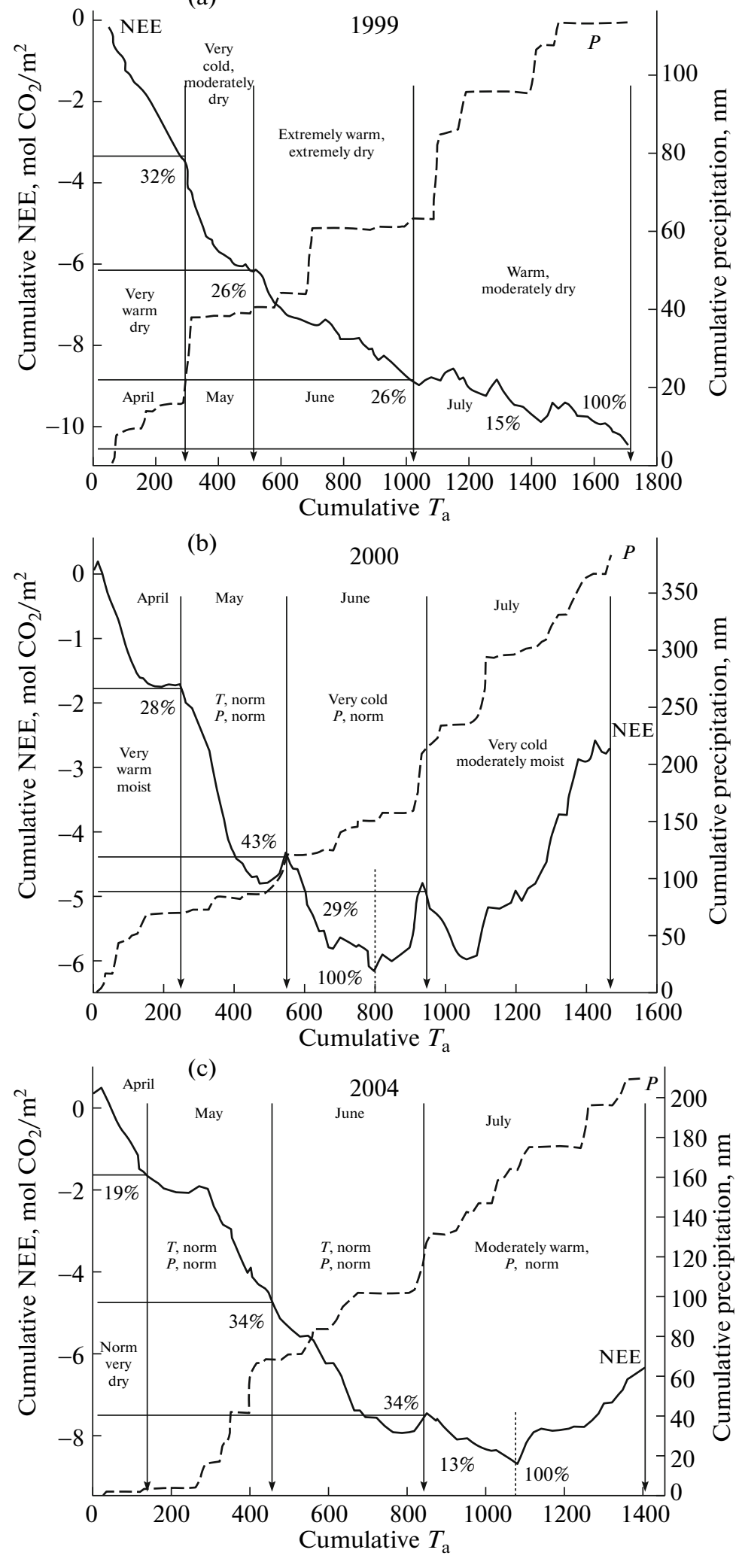

Fig. 2. Dependence of the cumulative NEE for the spruce forest with blueberry and peat moss growing in the Central Forest State Nature Biosphere Reserve for April-July on the accumulated sum of air temperatures $\left(T_{\mathrm{a}}>0^{\circ} \mathrm{C}\right)$ for 1999, 2000, and 2004. Negative NEE values correspond to $\mathrm{CO}_{2}$ absorption from the atmosphere. The dotted line indicates the cumulative precipitation dynamics. Numerals (\%) show the ratio of monthly sums of NEE to the maximal negative cumulative sum of NEE for the April-July. Vertical arrows indicate the temperature ranges according to months. Horizontal lines mark the boundaries of transitions with different moisture regimes. 
Data presented in Fig. 2 show a delayed response of ecosystems (via NEE) on the average temporal scale. In the middle of summer, the tendencies in changes of the cumulative NEE accumulated since the beginning of vegetation change for the opposite and, in the period from June to August, when the soil is warm, the total respiration of the ecosystem exceeds assimilation [1]. However, the onset of this critical point on the accumulated sum NNE curve depends on the preceding weather conditions. Analysis of three different seasons shows that it is very difficult to interpret data for the time lag estimation without taking into account the preceding time intervals (both the previous spring and the previous season; cf. 1999 and 2000). The main cause that hampers this analysis is the instability of meteorological conditions in different vegetation months in both current and subsequent seasons).

It is known that a climate norm can be estimated correctly only if the duration of measurement series is at least 30 years. With allowance of the life cycles of different species and community succession stages, it is clear that this requirement to the series length can be met only in the case of natural ecosystems with a weakly pronounced year-to-year variability of the vegetation cover (e.g., mature and overmature forests). The existing longest measurement data for the $\mathrm{H}_{2} \mathrm{O} / \mathrm{CO}_{2}$ exchange between the ecosystem and atmosphere give an idea on the scope of natural variability of the studied processes for period of at most 1015 years. On the basis of these data, it is possible to systematize the types of ecosystem responses to EWP and $\mathrm{CA}$ and to verify EME models. Apparently, EME models are the most real tool to estimating the norms of reaction of the basic ecosystem functions. It is also clear that the broadening of natural ecosystem monitoring network will create prerequisites for more realistic predictions of the biosphere responses to current and future climate changes.

\section{ACKNOWLEDGMENTS}

This study was supported by the Program of Basic Research of the Presidium of the Russian Academy of Sciences "Biodiversity."

\section{REFERENCES}

1. Vygodskaya, N.N., Abrazhko, V.I., Varlagin, A.V., et al., Lesovedenie, 2004, no. 1, pp. 3-22.

2. Baldocchi, D.D., Global Change Biol., 2003, vol. 9, pp. 479-492.

3. Ciais, P., Reichstein, M., Viovy, N., et al., Nature, 2005, vol. 437, pp. 529-533.

4. Frich, P., Alexander, L.V., Della-Marta, P., et al., Climate Res., 2002, vol. 19, pp. 193-212.

5. IPCC 2007 Climate Change 2007. The Physical Science Basis. Contribution of Working Group I to the IV Assessment Report of the IPCC, Cambridge: Cambridge Univ. Press.

6. Milyukova, I.M., Kolle, O., Varlagin, A., et al., Tellus, 2002, vol. 54B, no. 5, pp. 427-442.

7. Schär, C., Vidale, P.L., Lüthi, D., et al., Nature, 2004, vol. 427, pp. 332-336.

8. Suni, T., Berninger, F., Vesala, T., et al., Global Change Biol., 2003, vol. 9, pp. 1410-1426.

9. Vedin, H., Geograf. Ann., 1990, vol. 72A, pp. 151-155.

10. Walther, G.R., Post, E., Convey, P., et al., Nature, 2002, vol. 416, pp. 389-395. 